\title{
MICROENCAPSULATION OF FUNCTIONAL COMPONENTS IN THE FOOD TECHNOLOGY: PARTIALLY OPTIMISTIC VIEW
}

\author{
Alexei Baerle*, ORCID ID: 0000-0001-6392-9579 \\ Technical University of Moldova, 168 Stefan cel Mare Blvd., MD-2004, \\ Chișinău, Republic of Moldova \\ *Corresponding author: Alexei Baerle, alexei.baerle@chim.utm.md
}

Received: 07. 03. 2021

Accepted: 08. 16. 2021

\begin{abstract}
This work deals with the use of microencapsulation of biologically active compounds (BAC) as an alternative method of protection and prolongation of their functional properties in the food products. The main methods for the formation of microcapsules (MC) are considered. Biopolymer materials, suitable for MCs production, are outlined. Some technological solutions, suitable for microencapsulation and successfully used in other industries, present interest only for laboratory researches in the food science, but are not suitable for industrial scale food production. It is discussed why the methods of simple and complex coacervation, liposomal entrapment are thermodynamically advantageous for obtaining microcapsules in comparison with others. To achieve further progresses of microencapsulation in food technologies, the direct integration of the microencapsulation into the food production technological cycle is necessary. Products should initially have a texture and consistency that allow microcapsules to be resistant to premature aggregation. MCs should not exfoliate or break down, while execute their functions of protection and targeted delivery of biologically active compounds. Only high viscous colloidal systems, as traditional fermented dairy products (kefir, yoghurts, ice cream, curd and cheese) and fruit juices with pulp, are mostly suitable for supplementation of them by BACs using microencapsulation.
\end{abstract}

Keywords: biopolymers, biologically active compounds (BAC), coacervation, complex coacervation, fermented dairy products, microencapsulation's thermodynamic.

\section{Protection of biological activity: necessity of alternative "SMART" methodology}

Over the past decades, there have been fundamental changes in the field of nutritional science and in the way quality food is produced. The scientific concepts of optimal nutrition, based on functional foods of a new generation, have been developed in response to the consumers' needs of the foods with functional properties. These trends should have forced manufacturers to develop new technologies for the functional foods production [1]. The modern concept of nutrition suggests that in addition to nutritional and energy value, functional food products must have their own biological activity. It was found that the consumption of foods containing biologically active substances, promotes and really affects the maintenance of consumer's health, prevents the occurrence of various diseases [2]. 
However, until now, the food industry produces mainly traditional food products, which correspond in their properties to the traditional concept of a balanced diet. Despite the constant growth in food production in general, the share of functional food products is still relatively small. It seems that manufacturers are not ready to introduce functional ingredients into food, because they generate additional legal, technological, and economic problems. Functional ingredients or Biologically Active Compounds, BAC, interact with the main "stable" components of food (proteins, fats, carbohydrates and bio-metals). In traditional food cultures, the biological activity and functionality of nutrition is achieved using various fermented, mainly dairy products [3]. Unfortunately, these products have short shelf-life. It also seems at least absurd from the point of view of common sense to actively use synthetic antioxidants in order to protect the functional properties of biologically active substances introduced into the product. In order to run away from this (techno)logical error, attempts are being made to reduce the total quantity of the antioxidants used to protect the biological activity of various food components, at least, using effects of their synergistic interaction $[4,5]$.

One of the relatively new methods of stabilizing biologically active substances in food is their isolation from contact with other active food components by means of microencapsulation. Microencapsulation is a directed process of forming a thin, sufficiently strong, low-permeability shell with desired properties around small solid particles or their aggregates (granules), or around the liquid droplets of microencapsulated agent. The main goals of the microencapsulation are the reversible isolation of the biologically active content, its targeted delivery and controlled release. Thus, the main role of the microcapsules inclusion in the food products composition is to exclude direct contact of biologically active food components with the main composition, that is, with an aggressive environment for biologically active substances. Various high-molecular compounds are used as a building material for the shells of microcapsules. As part of a microcapsule, it is called a membrane, shell, carrier material, wall material, external phase, or matrix. The shell of the microcapsule separating the biologically active substance from the corrosive environment of the food product should be stable in the composition of the food product, but easily release its biologically active content when it enters the human gastrointestinal tract [6].

High-tech solutions as microencapsulation: why a food manufacturing is an exception?

Over the 70 years passed since the introduction of the term of "microencapsulation" into scientific circulation. Thousands of research papers with excellent experimental results, many thematic reviews and books have emphasized the potential of this method for creating functional food products [7 - 10]. However, a much larger number of works and patents are devoted to the microencapsulation of drugs, cosmetic components, and even ingredients that improve the functional properties of forages.

Why the microencapsulation, a smart technology for the engineering of products with desired properties, finds its place with great difficulty in modern food technology? There are enough reasons for this "paradox":

$\checkmark \quad$ The principle "The benefits of medicines outweigh the risks of treatment" opens the way for the use of a wide variety of modified or synthetic materials in the manufacture of medicines, inclussive using microencapsulation [11]. This trend is indirectly reflected in many experimental studies and analytical reviews [12 - 14]. However, this principle is completely 
inapplicable to food products of daily consumption, which should be tasty and absolutely safe without any amendments, involved by the probability theory;

$\checkmark \quad$ At the legislative and consumers level, there are much higher quality and safety requirements for food than for cosmetic products and, of course, for animal feed. At the same time, there are practically no "aesthetic" requirements for the appearance, texture and taste of veterinary drugs and feeds [15];

Also, there are less restrictions on the addition of synthetic polymers, crosslinking or surface-active agents, good for the production of microcapsules for cosmetics, veterinary medicine and in animal nutrition. Majority of these chemical agents cannot be used in food manufacturing;

$\checkmark \quad$ A significant increase in the price of the final product caused by microencapsulation will hardly be hardly accepted by the food industry with high risks and relatively low incomes, also will be hardly tolerated by the mass consumers [7];

$\checkmark \quad$ Food industry is generally characterized by high inertia of the and its adherence to traditions, which is supported by consumer mistrust not only for new food products, but to manufacturers and new technologies [16].

The combination of all mentioned factors leads to the fact that microencapsulation of functional food ingredients is perhaps the area of microencapsulation, which is most difficult for development (Figure 1).

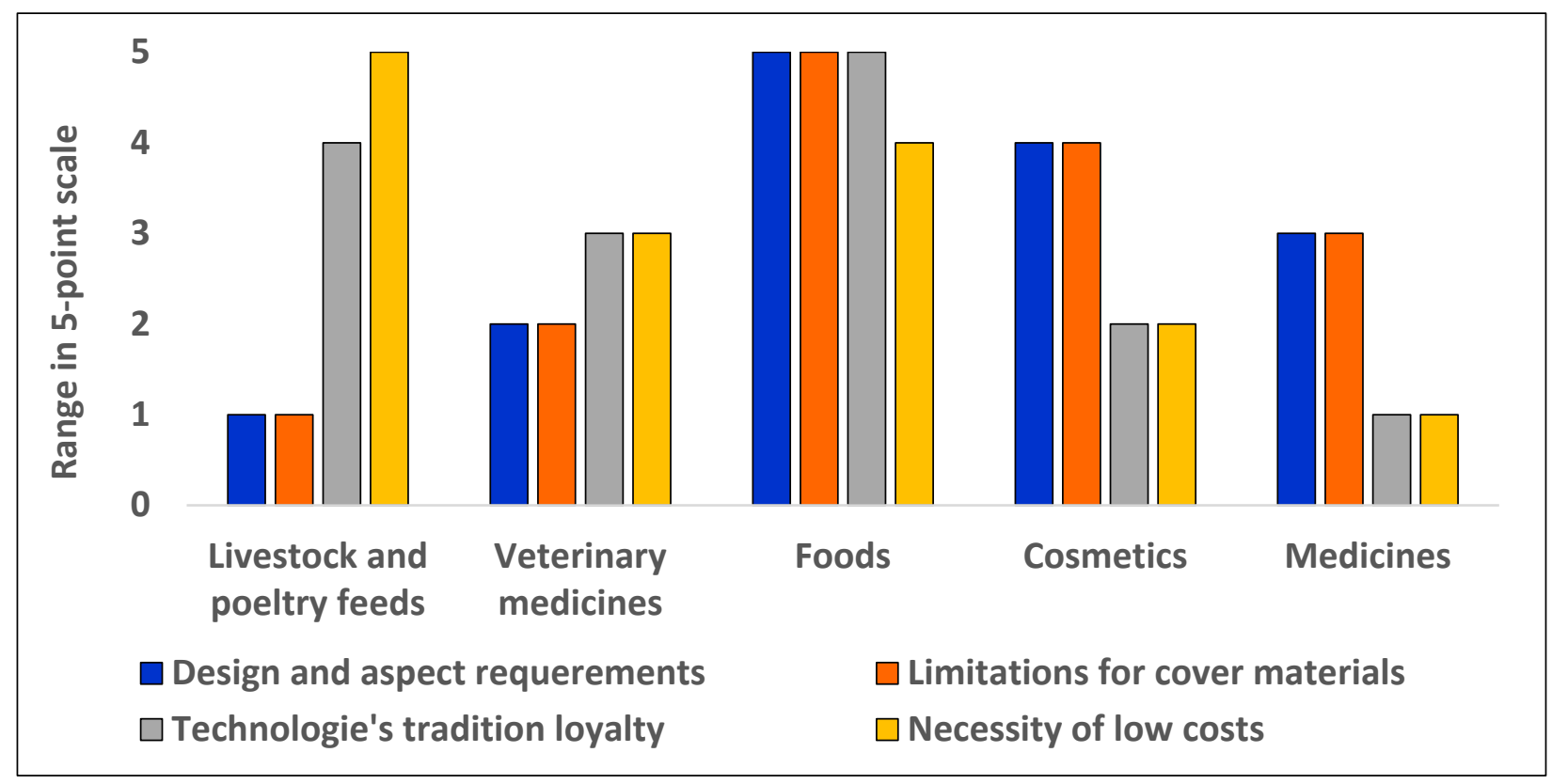

Figure 1. The uphill road: why is so difficult to incorporate microencapsulation into food technology?

Expectations regarding the MCs properties and benefits of are quite high and ambitious:

- $\quad$ They must immobilize the active substance during technological processes of food manufacturing by changing its state of aggregation, for example, converting liquids into a solid free-flowing form.

- They must prevent the degradation of biologically active substances as a result of interaction with the active components of the food product and oxygen, increase their stability during processing and in the final food product. 
- They should improve the safety of production, reduce odor and reduce the loss of volatile substances, flavors, mixtures containing volatile components.

- $\quad$ They should create the desired visual and texture effects, but not to create unwanted ones;

- $\quad$ Should regulate the properties of active ingredients: particle size, fat solubility or water solubility, mask their undesirable taste; change color;

- $\quad$ Should provide controlled release of the contents under specified conditions, including by regulating the permeability of the shell.

From the requirements and features, mentioned above, the super-goal of microencapsulation of food functional ingredients becomes clear:

Encapsulated food ingredients must not to add significantly values to the food costs - this way is not expected by consumers. The technologies used must ensure compliance with the requirements regarding the functional properties and food safety of microcapsules, their assimilation by the human organism, while not impairing the sensorial properties (taste, aspect and odour) of the product.

This overarching super-task is difficult to solve because its parts contradict each other. It is possible to create a science-intensive high-tech product only with resorting to a multilateral and multidisciplinary systematic approach. The solution of the microencapsulation tasks which are associated with the prevention of biologically active compounds degradation in food can be achieved through a targeted combination of scientific researches with ingeniously engineering innovations. But some of the ways which at first seems like breakthrough solutions are doomed to failure, because of "unfortunate" combination of different factors, given below.

\section{Structure and functional properties of microcapsules}

In function of particles diameter, the nano-capsules $(1 \mu \mathrm{m}>\boldsymbol{d}<1000 \mathrm{~nm})$ and microcapsules $(1 . .1000 \mu \mathrm{m})$ are mentioned in majority of references. Some of them, however, indicate that the size of microcapsules can reach up to 3-8 millimeters in diameter [17 - 19].

It should be emphasized that if the capsules are larger than $1 \mathrm{~mm}(1000 \mu \mathrm{m})$, they can no longer be considered "micro", even if they are obtained by microencapsulation methods. And it's not just because of the non-corresponding to formal size: the dimensions of capsules larger than $1 \mathrm{~mm}$ are not "negligible" in any way, significantly affecting the texture and sensory perception of any food product.

There are two main types of microcapsules: reservoir-type, $\boldsymbol{R}$, and matrix-type, $\boldsymbol{M}$. Reservoir-type microcapsules contain an external cover, surrounding the entire encapsulated content, in different sources named as "shell", "wall" or "membrane". Capsules of this type are also called "single-core", "mono-core" or "core-wall". The external cover of such microcapsules can be destroyed by the application of external physical, mechanical, or chemical action, leading to the release of the contents.

In the matrix type microcapsules, microencapsulated content is distributed over the carrier material, in the form of small particles or droplets, and represent discontinuous phase - suspension or emulsion of active compound in the carrier material. In the case of matrix type MCs and in the contrast to MCs of the reservoir type, the encapsulated active compound can be present on the surface of microcapsules if they do not have an additional "reservoir" coating. 
Table 1

The main types of nano- and microcapsules

\begin{tabular}{|c|c|c|c|c|}
\hline Particles & Type & Definition & Scheme & Refer. \\
\hline \multicolumn{5}{|l|}{ Biopolymer-based } \\
\hline $\begin{array}{l}\text { Micro- and } \\
\text { nanoparticles }\end{array}$ & $R$ & $\begin{array}{l}\text { Particles containing solid cores are covered with } \\
\text { other solid materials with protective properties }\end{array}$ & & $\begin{array}{l}12,13 \\
20,21\end{array}$ \\
\hline $\begin{array}{l}\text { Micro- and } \\
\text { nanocapsules }\end{array}$ & $R$ & $\begin{array}{l}\text { Spherical particles containing a liquid core and a } \\
\text { solid or gel-like elastic cover }\end{array}$ & & 23,23 \\
\hline $\begin{array}{l}\text { Multicore } \\
\text { microcapsules }\end{array}$ & $M$ & $\begin{array}{l}\text { Liquid droplets are distributed in a polymer } \\
\text { matrix representing three-dimensional baffles } \\
\text { net }\end{array}$ & & 24,25 \\
\hline $\begin{array}{l}\text { Porous and gel- } \\
\text { like matrix }\end{array}$ & $M$ & $\begin{array}{l}\text { Porous solid particles or gels, fulfilled with } \\
\text { active compounds }\end{array}$ & & 26 \\
\hline \multicolumn{5}{|c|}{ Lipid- and Surfactant-based nano- and microparticles* } \\
\hline Liposomes & $M$ & $\begin{array}{l}\text { Single-layer or multilayer phospholipid } \\
\text { membranes with hydrophilic content }\end{array}$ & & 13,27 \\
\hline Phytosomes & $R$ & $\begin{array}{l}\text { Active compounds are chemically bonded with } \\
\text { polar phospholipid parts, covered with non-polar }\end{array}$ & & 28,29 \\
\hline Niosomes & $R$ & $\begin{array}{l}\text { Particles with hydrophilic core, covered with } \\
\text { non-ionic surfactants and lipids }\end{array}$ & & 30 \\
\hline Colloidosomes & $R$ & $\begin{array}{l}\text { Particles formed by hydrophilic core and by shell } \\
\text { from solid nanoparticles (colloidal shell) }\end{array}$ & & 31,32 \\
\hline
\end{tabular}

A very detailed graphical analysis of the different types of lipid-based particles construction can be found in a recently published reviews [12, 13, 33]. Mixed type, reservoirmatrix, $\boldsymbol{R} \boldsymbol{M}$ microparticles also exist; for example, polynuclear matrices, additionally wrapped in a continuous shell [24]. Such group as "multiwall microcapsules" are also mentioned [25]. Conventionally, in this group it should be attributed liposomes and phytosomes, and "classical" MCs, with the shells obtained from charged biopolymers using Layer-by-Layer (Table 2). Sometimes dendrimers and micelles are mentioned as a nano-particles [13]. But these de facto high-molecular structures don't contain any clear boundary between two phases. Therefore, such monophasic colloidal formations are not be considered nanocapsules in unambiguous mode.

\section{Common encapsulation methods}

Microencapsulation of biologically active compounds in order to protect their biological activity is possibly using various technological solutions, more or less universal for various industries (Table 2). Emulsification is not strictly an independent method of microencapsulation. However, obtaining a stable BAC emulsion is the most important stage in preparation for Layer-by-Layer, (Simple) Coacervation or Complex Coacervation, both assisted or not by cross-linking. 
Microcapsule structure formation: basic methods

Briefly describing of nano- and microencapsulation method

Spray Drying (SD). A mixture containing BAS, biopolymers and surfactants is spraying in a hot chamber. A thin film is formed on the droplets surface because of evaporation of solvent.

Fluidized Bed Coating (FB). The finely dispersed solid covered with a film former by spraying, is "liquefied" with a stream of air.

Surface film formation occurs as a result of solvent evaporation.

Emulsification (EM). Relatively stable emulsions are obtained using high-speed homogenizers and surfactants. To obtain monodisperse emulsions, their fractionation is necessary, which is not easy.

Extrusion (EX). A continuous process in which molten components are dosed by pushing through an extrusion die, after which the mixture solidifies, sometimes the product is portioned after solidification.

Spray Cooling (SC). Liquid systems containing thermic unstable BAS or cell cultures are sprayed by injector in a chilled chamber, which leads to their solidification in the form of small particles.

Freeze-Drying $($ FD) = Lyophilization, Sublimation. Removal of water by freezing and sublimation to obtain a highly porous dispersed structure. Large amounts of cryoprotectants sometimes required.

Layer-by-Layer (LL). Sequentially covering of emulsion drops or solid particles by several layers of oppositely charged polyelectrolytes: pectins and polyuronic acid salts, (-); proteins, chitosan (+), etc.

(Simple) Coacervation (C). Spontaneous or induced condensation of a biopolymer or several biopolymers from a solution as a new solid phase on the surfaces of incapsulated material droplets.

Complex Coacervation (CC) - formation of a two-phase shell by electrostatic forces, $\mathrm{H}$-bonds or cross-linking between two different polymers, rather induced in stringent conditions, than spontaneous
Refer.

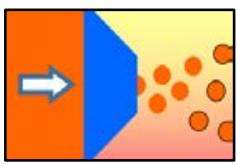

17 , $34-36$

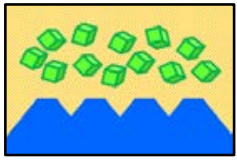

37,38

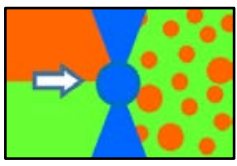

26 , $39-43$

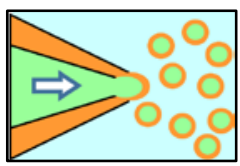

44,45

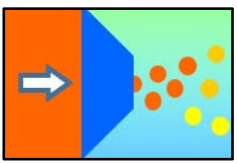

24 , 36,46

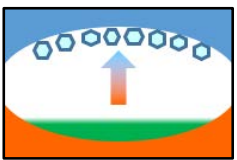

18,47

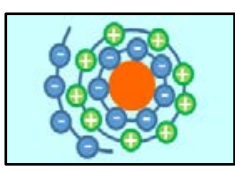

20,48
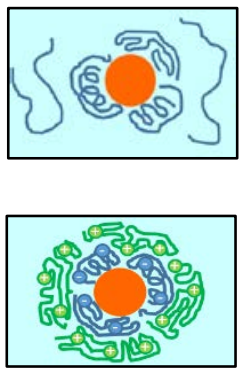

41,50

51

Complex coacervation should not be confused with the layer-by-layer method: in CC two thick layers, presenting different phases are formed, but in LL - several pairs (3 - 7) of thin layers, but which form only one common phase. It's also not Layer-by-Layer, when one or both phases in Complex Coacervation, are formed by oppositely charged polyelectrolytes $[49,52]$. Finally, it is no coacervation, if shell is formed from different initially solid materials [53]. 
Some methods, as electro-spray assisted extrusion [54, 55], represent a way to control microcapsules' size and to obtain monodisperse samples, but application of such method in food-industrial scale should be very expensive.

\section{Common edible biopolymeric materials for mc membranes (walls, shells) construction}

The shells of microcapsules used in the food industry must be edible and safe for humans. The shell material and other accompanying components of microcapsules should not disintegrate with the formation of harmful metabolites. They should create a barrier between the active content of microcapsules and an aggressive external environment, thus preventing premature degradation of biologically active substances and the formation of derivates without functional value. Ideally, the membranes themselves can have their own biological activity $[56,57]$.

These sometimes-conflicting requirements significantly reduce the variety of materials that can be used to obtain edible microcapsule shells. In order to form microcapsules, cover materials based on various natural and modified biopolymers are used (Table 3).

Table 3

Edible natural biopolymers as covering materials for microencapsulation

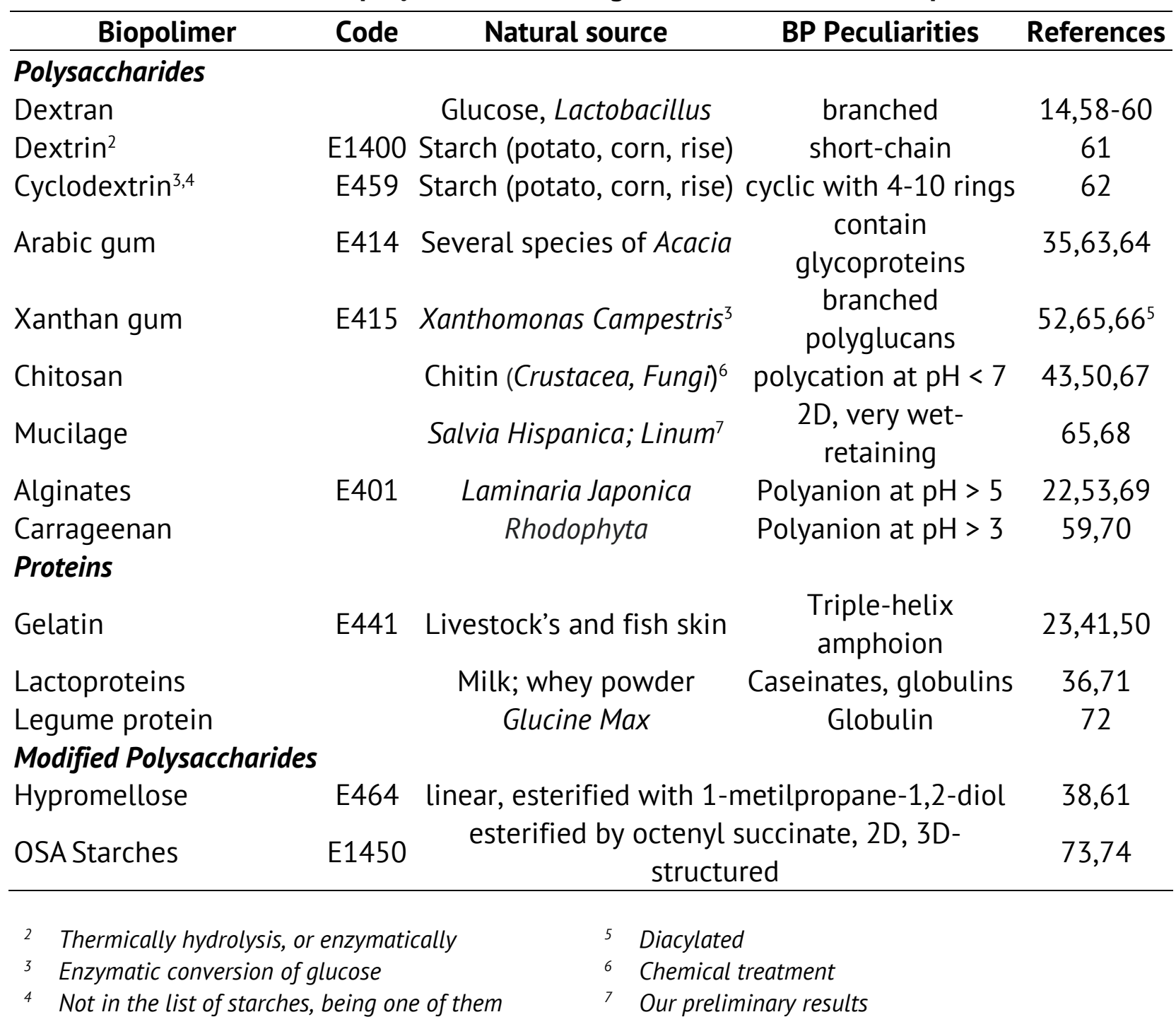


It should be noted that although dextrin (E1400) and cyclodextrin (E459) are modified starch derivatives, in Table 3 they are classified as natural, since they can be obtained from starch by hydrolysis or microbiological method [75, 76].

Exotically biopolymers, also common proteins and carbohydrates, actively interact with biologically active compounds [72]. Therefore, the kinetic incompatibility of the microencapsulated ingredient with the microcapsule shell is not at all excluded. Such incompatibility should not appear either immediately or during the microcapsules use in the foods. Incompatibility may be expressed either by the interaction with the shell content, or by gradual unwanted diffusion of the ingredient from the shell. Another possible reason for incompatibility may be the diffusion of destructive agents, for example, oxygen or catalytic enzymes, through the shell into the inner cavity of the microcapsule.

Table 4

Application areas for microencapsulated food ingredients

\begin{tabular}{cccc}
\hline Class: Examples & Methods & Expected microencapsulation results & Ref. \\
\hline $\begin{array}{c}\text { Minerals: } \mathrm{Ca}^{2+}, \mathrm{Mg}^{2+}, \mathrm{Fe}^{2+} \\
\text { or salts } \text { of } \mathrm{Fe}^{3+}, \mathrm{Zn}^{2+}\end{array}$ & $\mathrm{SD}, \mathrm{FB}$ & $\begin{array}{c}\text { Isolation of bio-metals (or minerals) in } \\
\text { order to reduce vitamins' degradation }\end{array}$ & 77,78
\end{tabular}

Acidity Regulators / Agents:

Weak acids and bases

Delivery to the intestine, bypassing the receptors in the oral cavity (taste masking)

Aroma: Oils, oil extracts, aromatic resins.

Solid powders which are activated during

19,58 cooking or in the mouth cavity

Sweet Taste Agents: Natural sugars, artificial sweeteners

$\mathrm{FB}, \mathrm{SD}$

Reducing hygroscopicity, improving distribution, prolonging taste

80,81

Food Dyes: Carotenoids, anthocyanins

CC, EX

Dosage, uniform distribution, protection over oxidation during storage.

Lipids: PUFA $\omega_{3}-\omega_{6}$, fish oil, SD, EM,

Prevention of redox destruction during 40-42, phospholipids, lecithin

LE $^{8} \quad$ storage, undesirable taste masking (fish oil)

Vitamines: liposoluble $A, D$, $E$, hydrosoluble $(B, C .$.

Control of release time, exclusion of

\section{Polyphenols}

SD, LL

Antibodies, Enzymes

$\lg Y$, amilase

Microorganisms and cells contact with the food matrix

LE,

Prevention of redox destruction during storage, undesirable taste masking

30,58 , 59,83

Stabilization in food matrix, targeted CC, LL delivery to the intestine, release control

Isolation from food environment, targeted $33,46,60,67$ C, $\mathrm{SA}^{9}$

8 Liposome Entrapment - a promising nanoencapsulation method, based on the formation of liposomes (phospholipidic spheres) and the capture of polar and non-polar substances by them

9 Self-assembly - a group of methods, characterized by relatively low enthalpy and entropy of MCs production

Contradictory influence of the sample's geometry on mcs properties and stability

The process of microencapsulation of liquid oils can be defined as the coating of an O/W emulsion droplets with a layer or several layers of a shell-forming material. It is generally 
known that the aggregate stability of colloidal systems increases with a decrease of particle size. However, no less important for the stability of the colloidal system is its polydispersity, that is, the profile characterizing the presence of particles of different diameters.

Microcapsules obtained from emulsions by any of the known methods will inherit the emulsions polydispersity.

The effect of polydispersity on the rheological properties of emulsions and, respectively, microcapsules, is ambiguous and contradictory, and, moreover, is closely related to the values of many other factors, one of which is the concentration of particles of the dispersed phase. The most chaotic and unpredictable seems to be a polydisperse emulsions, those that are formed during direct dispersion. Monodisperse emulsions and suspensions of microcapsules should have much lower entropy. At the same time, the geometry of a concentrated monodisperse system resembles a foam, and the process of adhesion of microcapsules, in turn, should repeat the mechanism of foam destruction [85]. Finally, concentrated mono- and bi-dispersed emulsions are most prone to coalescence (Figure 5).

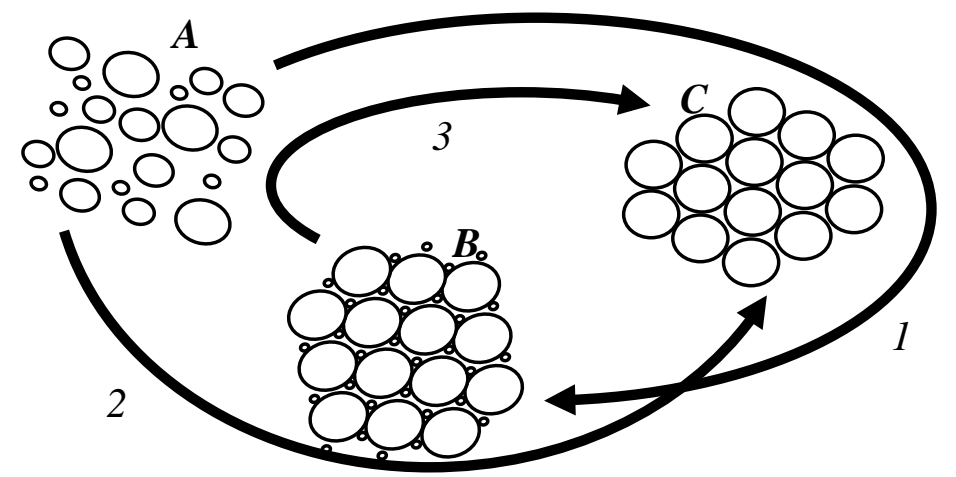

Figure 5. Effect of dispersion on the characteristics of emulsions and microcapsules:

A - diluted polydisperse emulsion; B - concentrate bi disperse emulsion;

C - concentrate monodisperse emulsion. Arrows show growth of the: 1 - density;

2 - structural organisation (negentropy); 3 - anti-coalescence stability.

\section{How to form stable mcs shell?}

The formation and strengthening of the shell around the microencapsulated substance occurs according to the thermomechanical, physicochemical and mixed mechanisms. Strengthening of the microcapsule shell is achieved in various ways:

Shell thickness increasing is not possible anytime, but if it is possible, leads to an overconsumption of the encapsulating agent or requires an increase in the number of microencapsulation cycles in the case of the LL process.

Increasing the MC-shell strength by removing of water excess from it. Coacervate shells of lipid-containing microcapsules can be viewed as a water-based gel that forms on the surface of a lipid droplet [31]. Various compounds can lead to syneresis of the coacervate layer. Necessity of a desiccant use to strengthen coacervate shells is fraught with the fact that the desiccant will perform its function only as long as it is part of the shell itself. Most widely used desiccant sodium sulfate - allowed food additive (E514), which has its own bitter taste.

To achieve the edibility of the coacervate casing (and of MC as a whole), the desiccant must be partially or completely removed. Relative rarely used (due to information from accessible sources) dialysis and electrodialysis can serve as one of the promising methods of removing a desiccant excess from the microcapsules [86]. Though, any attempts to 
completely remove the desiccant from pure-Gelatin simple coacervation shells lead to shells destabilization and release of active content [69].

Cross-linking. Cross-linking is the strengthening of MCs polymeric membranes at the molecular level by means of bi- or polyfunctional agents. There are physical (ionic) and chemical cross-linking. Ionic cross-linking involves the interaction of polymer ions with oppositively-charged polyions. The allowed food additives tripolyphosphates (E451) and citrates (E331) can be used as polyanions. Such a mechanism may seem similar to Layer-byLayer, but this is not entirely true. In the LL technique, several oppositely charged layers of biopolymers or more or less the same thickness are successively applied [20]. The crosslinking technique involves a one-time creation of a consistent shell, which is then exposed to a binding agent. Effective results can be achieved by a combination of ionic cross-linking and the addition of agents that promote the formation of intermolecular hydrogen bonds [57]. Chemical cross-linking involves the covalent binding of linear biopolymer molecules and the formation of a three-dimensional net structure. For proteins, in particular, gelatin, this method is the binding of glutamine and lysine by amide "bridges" under the action of the enzyme trans-glutaminase [40]. Various types of cross-linking, i.e. ionic and covalent, if they are used separately, all other conditions being equal in similar systems, do not significantly affect the shell thickness and the microcapsules size. However, in the case of a combination of ionic and chemical crosslinking, microcapsules may become more unstable in presence of an excess of ionic crosslinking agent, for example, Na-TPP [87].
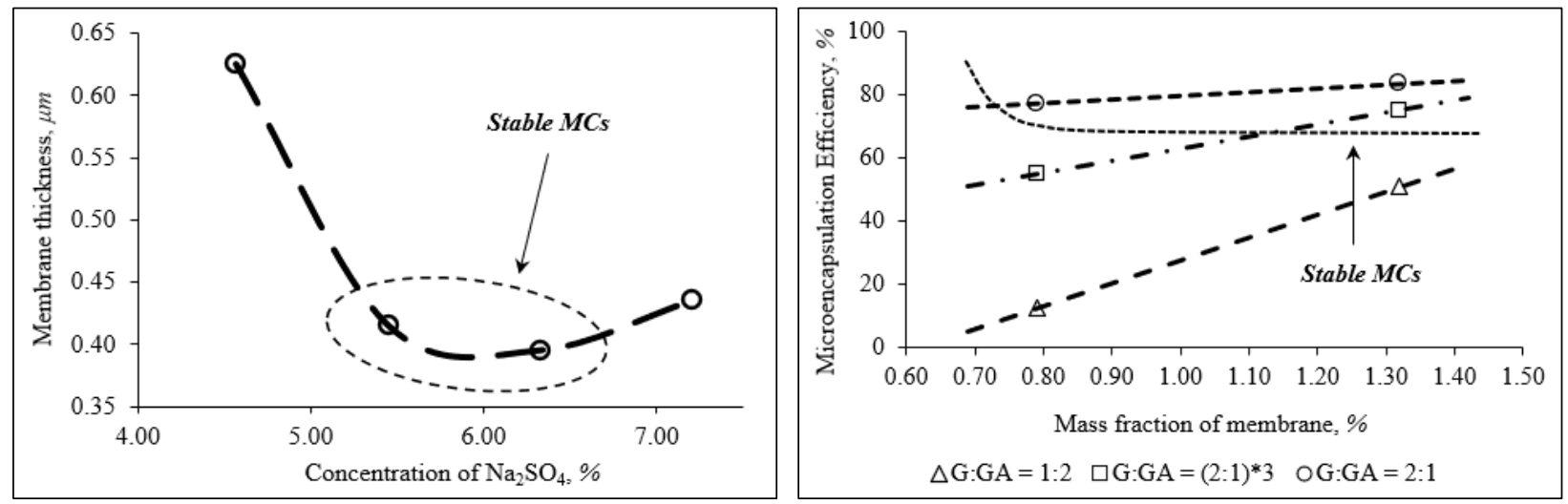

Figure 6. Influence of different Factors to MC stability: Left: Reduction of membrane thickness by influence of sodium sulphate - [69]; Right: Influence of wall material (Gelatin: Gum Arabic) relationship and quantity - recalculated from data, published in [63].

The influence of various factors on the stability of microcapsules and the efficiency of microencapsulation does not always correspond to "natural" expectations. For example, we have found that only certain average concentrations of sodium sulfate lead to the formation of stable gelatinous alginate shells around the walnut oil droplets [69]. Detailed studies of the gelatin: gum arabic system in microencapsulation of olive oil show that an increase in the amount of wall material does not always lead to an increase in the efficiency of microencapsulation [63]. In other words, for a microcapsule containing liquid oil, both a thin and too thick shell are harmful. Even double reduction of tension on the Oil/Water interface in the emulsions formed in the biopolymer solutions [88], is able to maintain on surface only a thin monomolecular biopolymeric layer; a thick layer, possible, is destroyed by gravitational stratification [85]. 


\section{On the thermodynamics and efficiency of the microencapsulation process}

Direct energy consumption for food production is $4-7 \mathrm{MJ} / \mathrm{kg}$, and for some products it reaches 10-17 MJ/kg [89]. Therefore, according to actual trends, in the manufacturing of any new food products, energy consumption should not increase significantly in comparison with traditional processes [90]. Spray Drying, SD, and Fluid Beds, FB, require elevated temperatures; Freeze Drying, FD, and Spray Cooling, SC, on the other hand, require cooling energy. Another energy-consuming vector is a large number of stages of the process, which will lead to an increase systems negentropy, that is, to increase a work, time and energy spent on the MCs production.

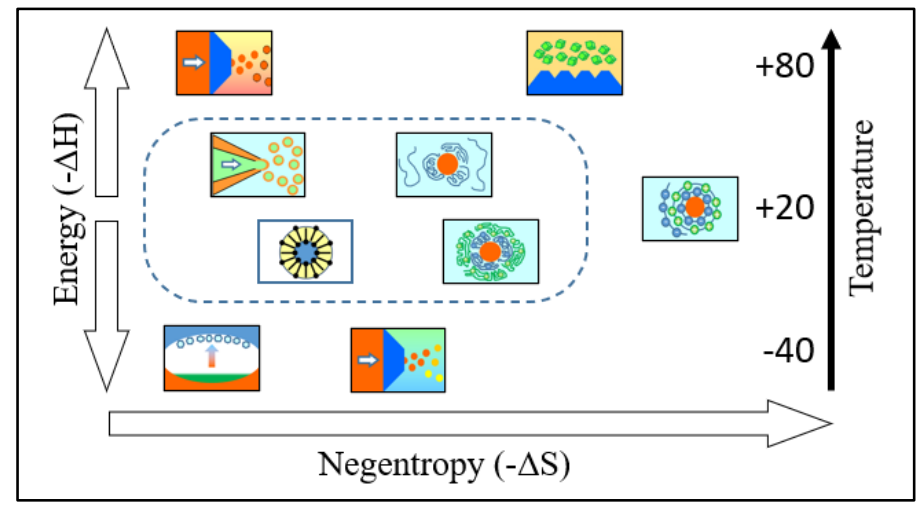

Figure 7. Thermodynamic, hence, energetic and economic restrictions for obtaining of edible microcapsules. BAC-friendly, relative energetic low methods, are dotted.

As is shown in the Figure 4, extrusion refers to the category of low energy microencapsulation methods. But then another problem arises. It is easy to extrude large capsules, which is done industrially very successfully. The reducing the linear dimensions $(\mathrm{cm}, \mathrm{mm})$ to microns $(\mu \mathrm{m})$ practically does not reduce the time, required for the production of one unit. Thus, the production by extrusion of $1 \mathrm{~cm}^{3}$ of microcapsules with a diameter of 100 microns will require... nothing at all, 1909859, $\approx 2 \cdot 10^{6}$ time longer, than the production of single big pharmaceutical capsule with a volume of $1 \mathrm{~cm}^{3}$. Recently, very significant advances have been made in the development of technologies for obtaining monodisperse emulsions and microcapsules based on them [91]. One-piece matrix, containing up to 1000 dispensing nozzles, can be produced by 3D printing techniques. But nevertheless, even such truly revolutionary solutions are still laboratory, but not industrial. In order to obtain 2000000 microcapsules per unit of time (with a total volume of only $1 \mathrm{~cm}^{3}$ ), you will need to have 2000 such matrices with 1000 nozzles each...

Thus, from all existing microencapsulation methods, it seems that only liposomal entrapment (LE) and both types of coacervation: simple (C), and complex (CC), are realistically suitable for use in the manufacturing of relative available food-grade microcapsules.

\section{Controlled release of biologically active compounds: how not to open the mc-shells at the wrong time and place, but to open it in the correct ones?}

As was already noted, the food industry is strictly limited in the use of related materials, due to which developments in microencapsulation in the production of innovative drugs are ahead of those in the food manufacturing field. For example, methods of nanocapsulation of chemotherapeutic drugs in elastin-like membranes are being developed, the opening of which is activated by components built into the membrane; encapsulated content 
release take place predominantly by cancer cells [92]. However, the engineering of microcapsules at a similar level is quite possible for functional food products, when, for example, the active substance is released only under the combined action of factors ( $\mathrm{pH}$, temperature and enzymes) corresponding to the conditions of the human intestine and even its specific zones [55, 93, 94]. Another interesting example of $M C$ engineering is the technology of cheese production, in which a controlled release of microencapsulated bixin occurs in a ripening product due to the sequential action of proteases and lipases on microcapsules containing this food coloring [10].

\section{Mathematical modelling of microcapsules properties}

If microcapsules were obtained by simple or complex coacervation only from edible compounds, is not always possible, and most importantly, is always not rationally to isolate them from the supernatant and to obtain they in solid state. Isolation from the supernatant involves additional filtration, energy-intensive spray drying or sublimation steps. Also, the attempts to isolate edible microcapsules in dry form fails, because is impossible to avoid their sintering [23]. These microcapsules (especially, those obtained by simple coacervation) are relatively stable as long as they stay in their own supernatant environment. This limits the possibilities for the direct instrumental determinations of some food microcapsules parameters. For the numerical estimation of microencapsulation parameters, it is reasonable to resort to a combination of possible direct measurements and indirect evaluative methods.

Microencapsulation yield, also called recovery [51], is the practical percentage of obtained microcapsules $\left(m_{M C}^{p}\right)$, formed from the total initial mass of microencapsulated core material $\left(m_{c . m .}^{0}\right)$, and of initial mass of shell materials used $\left(m_{s . m .}^{0}\right)$ :

$$
Y_{M C}=\frac{m_{M C}^{p}}{m_{s . m .}^{i n .}+m_{c . m .}^{i n .}} \cdot 100 \%
$$

Microencapsulation efficiency, $E_{M C}$ [83], also named Loading Capacity, LC [52], is the percent ratio of the practically microencapsulated core material $\left(m_{c . m .}^{p}\right)$ vs initial mass of active core material (biologically active compounds) introduced into microencapsulation process:

$$
E_{M C}=L C=\frac{m_{c . m .}^{p}}{m_{c . m .}^{\text {in. }}} \cdot 100 \%
$$

Core material volumetric fraction [93], $\varphi_{c . m .}$, in the microcapsules of radius $\boldsymbol{r}$ (diameter d) with a known thickness $\boldsymbol{h}$, may be calculated by the equation:

$$
\varphi_{c . m .}=\frac{V_{c . m .}^{0}}{V_{M C}^{0}}=\frac{(r-h)^{3}}{r^{3}}=\frac{(d-2 h)^{3}}{d^{3}}
$$

Distribution width (Span). The distribution width can be estimated as:

$$
\text { Span }=\frac{D_{90 \%}-D_{10 \%}}{D_{50 \%}}
$$

in which $D_{i \%}$ is diameter, below which $i \%$ of sample is contained $[6,95]$. 
Polydispersity characterizes the size distribution of microcapsules in much more detail than the distribution width. In a test sample containing microcapsules with a total volume $\sum V$, polydispersity can be expressed by a distribution curve, in which the volumetric fraction of microcapsules, $\varphi_{i}$ is a function of their radius $r_{i}$ [22]

$$
\varphi_{r_{i}}=\frac{V_{r_{i}}}{\sum V}
$$

Experimental values of radius or diameter can be obtained by counting of representative samples consisting of not less than 100-150 microcapsules in magnified microscopic images $[22,88]$.
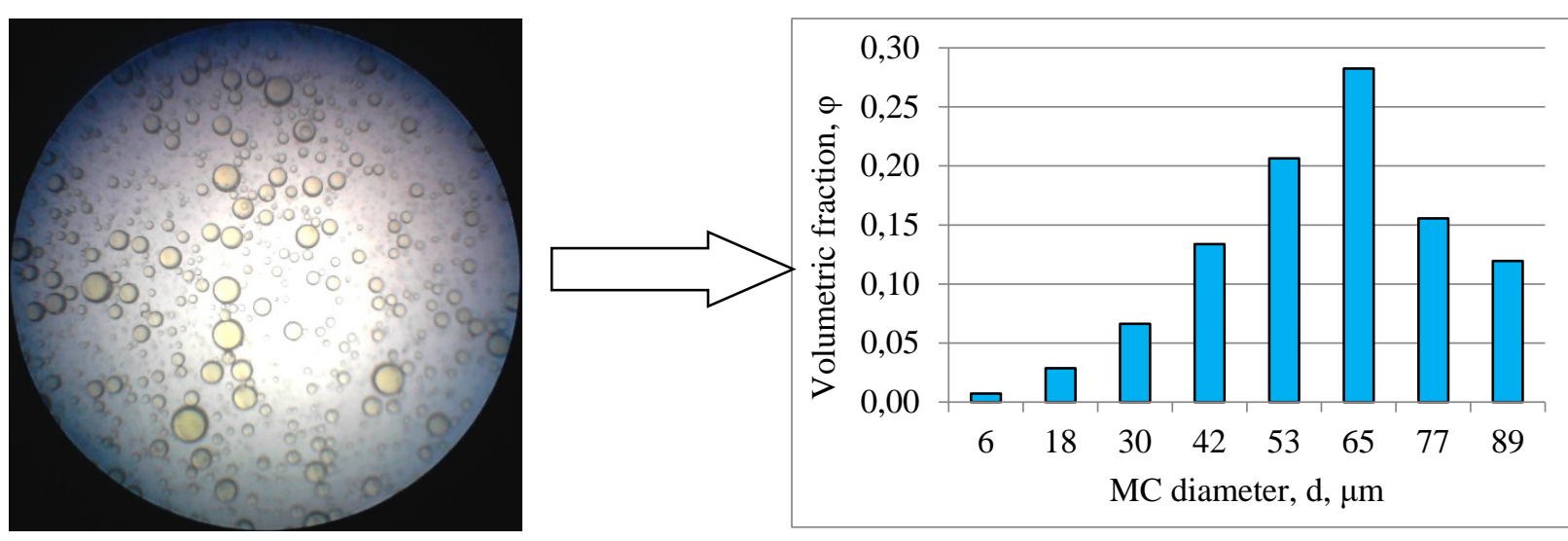

Figure 8. Transformation of MC image into "normal distribution".

\section{On the effect of microcapsules on foods sensory perception}

Appearance and consistency of food systems are of great importance to the consumer. Therefore it is important that the microcapsules be distributed evenly throughout the food product without forming a separate phase. One of the factors of such a uniform distribution is the equal density of microcapsules and the food environment in which they are located, $\rho_{M C}=\rho_{\text {env }}$.

$$
\begin{gathered}
\frac{\boldsymbol{V}_{\text {shell }}}{\boldsymbol{V}_{\text {core }}}=\frac{\boldsymbol{m}_{\text {shell }} \cdot \boldsymbol{\rho}_{\text {core }}}{\boldsymbol{m}_{\text {core }} \cdot \boldsymbol{\rho}_{\text {shell }}}=\frac{\boldsymbol{R}_{\boldsymbol{M C}}^{\mathbf{3}}-\boldsymbol{R}_{\text {core }}^{\mathbf{3}}}{\boldsymbol{R}_{\text {core }}^{\mathbf{3}}} \\
\left(\rho_{M C}-\rho_{\text {Core }}\right) \cdot R_{\text {Core }}^{3}+2 L\left(\rho_{M C}-\rho_{\text {Shell }}\right) \cdot R_{\text {Core }}^{2}+ \\
+2 L^{2}\left(\rho_{M C}-\rho_{\text {Shell }}\right) \cdot R_{\text {Core }}+\left(\rho_{M C}-\rho_{\text {Shell }}\right) \cdot L^{3}=0 \\
\left(\boldsymbol{\rho}_{\text {env }}-\boldsymbol{\rho}_{\text {core }}\right) \boldsymbol{R}_{\text {core }}^{3}+\mathbf{2} \boldsymbol{L} \boldsymbol{R}_{\text {core }} \boldsymbol{R}_{\boldsymbol{M C}}\left(\boldsymbol{\rho}_{\text {env }}-\boldsymbol{\rho}_{\text {shell }}\right)+\left(\boldsymbol{\rho}_{\text {env }}-\boldsymbol{\rho}_{\text {shell }}\right) \boldsymbol{L}^{\mathbf{3}}=\mathbf{0}
\end{gathered}
$$

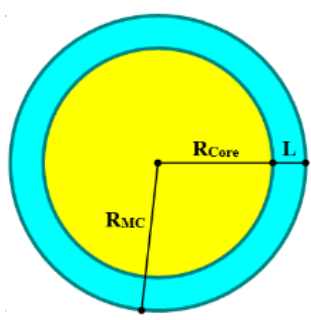

The solution of the last third-order equation using the Cardano algorithm [96] makes it possible to mathematically calculate the practical values of the MC size at which the processes of their sedimentation or stratification in model or real systems are minimized.

\section{About the foods, suitable for mcs introduction}

The introduction of microcapsules into milk and cream led to their uneven distribution in the volume of the product, and even to the formation of separate layers and clots consisting of microcapsules. Dairy products, obtained from fermented milk (fat-reached kefir and sour 
cream), turned out to be friendlier to the microcapsules, introduced into them [97]. The consistency of kefir and sour cream allowed the microcapsules to be distributed evenly throughout the volume of these products, at the same time, without changing their sensorial characteristics. Using various nanoencapsulation techniques, it is possible to obtain a wide range of food products enriched with encapsulated BACs, including yoghurts, fruit juices, and some bread and meat products [98].

Recently, it seems, gradually comes the understanding that the success of microencapsulation of biologically active substances specifically for food products is closely related to the thermodynamic characteristics of the corresponding methods. It is not accidentally mentioned, that the coacervation process (also named "phase inversion") - is predominantly isothermal [99]. The use of already existing working technological lines, taking into account the thermodynamics of the innovative processes introduced into them, allows the creation of innovative food products with low negentropy [100]. A similar approach should finally bring microencapsulation to the level of mass industrial use.

\section{Conclusion}

Microencapsulation technologies, which have proven themselves in the production of convenient dosage forms, in cosmetology and many other fields, still remain mostly only "promising" for the food industry.

Scientific and technological still require a solution for number of challenges. The kinetic instability and solubility of natural biopolymer casings in food environments limits the scope of application of microcapsules in food products. The search for new edible compositions based on natural polymers and fibers for stable microcapsule shells should be continued. Ideally, all accompanying ingredients should have a status "quantum satis" for use in food manufacturing.

The possibilities of BAC microencapsulation will always be limited by the temperature regimes acceptable for working with biologically active compounds and with useful microflora, because these are often existing in a narrow temperature range. An increase in the cost of a product during the modernization of its production technology is most sensitive for the consumer. The multistage process of microencapsulation, the practical impossibility of making it continuous, and therefore additional costs, reduce the possibilities of application of known technological solutions for the MCs production for foods. Serious questions are also raised by the possibility of sterilization of microcapsules and their long-term storage as such, as a separate product.

It has been shown by using thermodynamic functions, that such methods of $M C$ production as simple coacervation, complex coacervation and liposomal entrapment are thermodynamically reasonable for BACs nano- and microencapsulation.

The implementation of these three basic methods is a big challenge for equipment developers: these three methods still exist in the form of laboratory solutions, and their elegant embodiment in the form of working industrial technology has not been realized yet.

Food-grade microcapsules should release biologically active compounds or beneficial microflora only in the desired sector of the digestive tract, that is, the release should not occur in the composition of food, but should be activated only by certain digestive enzymes.

The real ways of using microcapsules in food technologies are associated with the direct integration of the microencapsulation process into the technological cycle of the production of specific food products. Moreover, these products should initially have a texture 
and consistency that allow microcapsules to be aggregation resistant, not to exfoliate or break down prematurely, while maintaining their functions of protection and targeted delivery of biologically active compounds. Such products should be highly viscous colloidal systems. Thereby, the traditional fermented milk products and yoghurts, ice cream and juices with pulp, curd and cheese, are mostly suitable for supplementation of them by BAC using microencapsulation.

Acknowledgements: We express our gratitude to the National Research and Development Council of the Republic of Moldova for the funding of Postdoctoral Grant 20.00208.1908.02 - "Prolongation of biologically active compounds functionality and its protection in food compositions", within which this work was developed. Heartful gratitude to Prof. Pavel Tatarov and Prof. Rodica Sturza - Technical University of Moldova.

\section{References}

1. FAO: Draft Vision and Strategy for FAO's work in Nutrition. [online, accessed 03.08.2021] http://www.fao.org/3/ne699en/ne699en.pdf - accessed 25.07.2021

2. Ortega A.M.M., Campos M.R.S. Bioactive Compounds as Therapeutic Alternatives. In: CAMPOS, M.R.S., ed. Bioactive Compounds. Cambridge, Woodhead Publishing, 2019, pp. 247 - 264.

3. Singh V.P. Recent approaches in food bio-preservation - a review. Open Vet. J., 2018; 8(1), pp. 104 - 111.

4. Baerle A., Popovici C., Radu O., Tatarov P. Effect of Synthetic Antioxidants on the Oxidative Stability of Cold Pressed Walnut Oil. Journal of Food and Packaging Science, Techniques and Technologies, 2016 (9), p. 19 - 24.

5. Radu O. Food compositions based on walnut oil (Juglans regia L.), resistant to oxidative degradation. PhD Thesis in Biological and Chemical Technologies in the Food Industry. Chișinău, Technical University of Moldova, 2020, 150p. - in Romanian.

6. Guedes Silva K.C., Bourbon A.I., Pastrana L., Kawazoe Sato A.C. Emulsion-filled hydrogels for food applications: Influence of pH on emulsion stability and a coating on microgels protection. Food \& Function, accepted paper, 2020. DOI: 10.1039/DOFO01198C

7. Amaral P.H.R., Andrade P.L., De Conto L.C. Microencapsulation and Its Uses in Food Science and Technology: A Review. In: SALAÜN F., ed. Microencapsulation - Processes, Technologies and Industrial Applications. IntechOpen, 2019, https://www.intechopen.com/chapters/67432 - accessed 03.08.2021

8. Ferreira S., Nicoletti V.R. Use of a tubular heat exchanger to achieve complex coacervation in a semicontinuous process: Effects of capsules curing temperature and shear rate. Journal of Food Engineering. Vol. 310, 2021. [online, accessed 03.08.2021] - https://doi.org/10.1016/j.jfoodeng.2021.110698.

9. De Matos F.E., Thomazini M., Trindade M.A., Favaro-Trindade C. Application of free or encapsulated Vitamin C to chicken frankfurter sausage by spray chilling: Physicochemical characteristics, stability and sensory acceptance. Braz. J. of Food Technology, 2015, 18(4), pp. 322 - 331 - in Portuguese

10.Sharma P., Segat A., Kelly A.L., Sheehan J.J. Colorants in cheese manufacture: Production, chemistry, interactions and regulation. Comp. Review in Food Science and Food Safety, 2020 (19), pp. 1220 - 1242.

11. Raynor T. The benefits of medicines outweigh the risks of treatment - says who? The Pharmaceutical Journal, 2013, Vol. 290, p. 616.

12. Mahato R. Multifunctional Micro- and Nanoparticles - In: MITRA, A.K., CHOLKAR, K., MANDAL, A. Eds: Micro and Nano Technologies Emerging Nanotechnologies for Diagnostics, Drug Delivery and Medical Devices. Elsevier, 2017, pp. 21-43.

13.Ciucă A.G., Grecu C.I., Rotărescu P., Gheorghe I., Bolocan A., Grumezescu A.M., Holban A.M., Andronescu E. Nanostructures for drug delivery: pharmacokinetic and toxicological aspects - IN: AndronescuE., Grumezescu A.M. Eds. Micro and Nano Technologies, Nanostructures for Drug Delivery. Elsevier, 2017, pp. 941-957.

14. Vasile C., Pamfil D., Stoleru E., Baican M. New Developments in Medical Applications of Hybrid Hydrogels Containing Natural Polymers. Molecules, 2020, 25 (7), 1539.

15. Codex (Alimentarius) general standard for contaminants and toxins in food and feed. www.fao.org/fileadmin/user_upload/livestockgov/documents/1_CXS_193e.pdf - accessed 05.08.2021

16. Nunes K. Consumers continue to mistrust food and beverage manufacturers. Accessed 03.08.2021 https://www.foodbusinessnews.net/articles/12058 
17. Parvathy U., Jeyakumari A. Microencapsulation and Spray Drying Technology. In: Protocols for the production of high value secondary products from industrial fish and shellfish processing. Bindu J., Sreejith S., and Sarika K. Eds. Central Institute of Fisheries Technology. Cochin, 2018, pp. 140 - 147.

18. Da Silva P.T., Fries L.L.M., De Menezes C.R., Holkem A.T., Schwan C.L., Wigmann É.F., De Oliveira Bastos J., De Bona Da Silva C. Microencapsulation: concepts, mechanisms, methods and some applications in food technology. Ciência Rural, 2014, 44(7), pp. 1304 - 1311.

19. Gupta S., Khan S., Muzafar M., Kushwaha M., Yadav A.K., Gupta A.P. Encapsulation: entrapping essential oil/flavors/aromas in food. In: Grumezescu A.M., ed.: Nanotechnology in the Agri-Food Industry, Encapsulations. Academic Press, 2016, pp. 229 - 268.

20. Kalaycioglu G.D., Aydogan N. Layer-by-layer coated microcapsules with lipid nanodomains for dual-drug delivery. Colloids and Surfaces A: Physicochemical and Engineering Aspects. 2020, 584, 124037.

21. Radulova G.M., Slavova T.G., Kralchevsky P.A., Basheva E.S., Marinova K.G., Danov K.D. Encapsulation of oils and fragrances by core-in-shell structures from silica particles, polymers and surfactants: The brick-andmortar concept. Colloids and Surfaces A: Physicochemical and Engineering Aspects, 2018, 559, pp. 351 - 364.

22. Baerle A., Dimova O., Zadorojnai L., Tatarov P., Zenkovich A. Electrophoresis of Oil-Containing Edible Microcapsules with Protein-Polyuronic Shells. Ukrainian Food J., 2014, 3(2), pp. 211 - 217.

23. Baerle A., Dimova O., Urumoglova I., Tatarov P., Zadorojnai L. Phase Diagram of Gelatine-Polyuronate Colloids: its Application for Microencapsulation and Not Only. Chemistry Journal of Moldova. 2016, 16 (1), pp. $97-105$.

24. Favaro-Trindade C., Okuro P.K. Encapsulation via Spray Chilling / Cooling / Congealing. In: MISHRA, M. ed. Handbook of Encapsulation and Controlled Release. CRC Press, 2015, pp. 71 - 86.

25. Bakry A.M., Abbas SH., Ali B., Majeed H., Abouelwafa M.Y., Mousa A.H., Liang L. Microencapsulation of Oils: A Comprehensive Review of Benefits, Techniques, and Applications. Comprehensive Reviews in Food Science and Food Safety. 2015, 15(1), pp. 143 - 182.

26. Dabija A., Nechifor I. Study regarding the microencapsulation of food ingredients in alginates. Annals. Food Science and Technology. 2015, 16, (1), pp. 20 - 26.

27.Tsai W.Ch., Rizvi S.S.H. Liposomal microencapsulation using the conventional methods and novel supercritical fluid processes. Trends in Food Science \& Technology, 2016, 55, pp. 61 - 71.

28. Babazadeh A., Jafari S.M., Shi, B. Encapsulation of food ingredients by nanophytosomes. In: Jafari S.M. ed. Nanoencapsulation in the Food Industry. Lipid-Based Nanostructures for Food Encapsulation Purposes. Academic Press, 2019, pp. 405 - 443.

29. Awasthi R., Kulkarni G., Pawar V. Phytosomes: An Approach to Increase the Bioavailability of Plant Extracts. International Journal of Pharmacy and Pharmaceutical Sciences. 2011, 3, pp. 1 - 3.

30. Rashidinejad A., Boostani S., Babazadeh A., Rehman A., Rezaei A., Akbari-Alavijeh S., Shaddel R., Jafari S.M. Opportunities and challenges for the nano-delivery of green tea catechins in functional foods. Food Research International, 2021, 142(2), 110186.

31. Lengyel M., Kállai-Szabó N., Antal V., Laki A.J., Antal I. Microparticles, Microspheres, and Microcapsules for Advanced Drug Delivery. Sci. Pharm. 2019, 87 (3), 20.

32. Purkayastha M., Manhar A., Mandal M., Mahanta Ch. Industrial Waste-Derived Nanoparticles and Microspheres Can Be Potent Antimicrobial and Functional Ingredients. Journal of Applied Chemistry, 2014, pp. 1 - 12.

33. Kyriakoudi A., Spanidi E., Mourtzinos I., Gardikis K. Innovative Delivery Systems Loaded with Plant Bioactive Ingredients: Formulation Approaches and Applications. Plants, 2021, 10, 1238.

34. Mohammed N.K., Tan C.P., Manap Y.A., Muhialdin B.J., Hussin ASM. Spray Drying for the Encapsulation of Oils - a Review. Molecules. 2020, 25(17), 3873.

35. Corrêa-Filho L.C., Lourenço M.M., Moldão-Martins M., Alves V.D. Microencapsulation of $\beta$-Carotene by Spray Drying: Effect of Wall Material Concentration and Drying Inlet Temperature. International Journal of Food Science, 2019, 8914852.

36. Mis-Solval K.E., Jiang N., Yuan M., Joo K.H., Cavender G.A. The Effect of the Ultra-High-Pressure Homogenization of Protein Encapsulants on the Survivability of Probiotic Cultures after Spray Drying. Foods. 2019, 8(12) : 689.

37. Mohylyuk V., Patel K., Scott N. Richardson C., Murnane D., Liu F. Wurster Fluidized Bed Coating of Microparticles: Towards Scalable Production of Oral Sustained-Release Liquid Medicines for Patients with Swallowing Difficulties. AAPS PharmSciTech, 2020, 21 (3). 
38.Zhang R., Hoffmann T., Tsotsas E. Novel Technique for Coating of Fine Particles Using Fluidized Bed and Aerosol Atomizer. Processes, 2020, 8, 1525.

39. Colucci G., Santamaria-Echart A., Silva S.C., Fernandes I., Sipoli C.C., Barreiro M.F. Development of Water-inOil Emulsions as Delivery Vehicles and Testing with a Natural Antimicrobial Extract. Molecules, 25 (9), 2105.

40. Gharibzahedi S.M.T., George S., Greiner R., Estevinho B.N., Frutos Fernández M.J., Mcclements D.J., Roohinejad S. New Trends in the Microencapsulation of Functional Fatty Acid-Rich Oils Using Transglutaminase Catalyzed Crosslinking. Comprihensive Reviews in Food Science and Food Safety. 2018, 17(2), p. 274 - 289. doi: 10.1111/1541-4337.12324.

41. Ferreira S., Nicoletti V.R. Complex coacervation assisted by a two-fluid nozzle for microencapsulation of ginger oil: Effect of atomization parameters. Food Research International, 2020, 138 (Pt B):109828.

42. Amran M., Zulfakar M.H., Danik M.F., Abdullah M., Shamsuddin A.F. A new alternative for intravenous lipid emulsion $20 \% \mathrm{w} / \mathrm{w}$ from superolein oil and its effect on lipid and liver profiles in an animal model. Journal of Faculty of Pharmacy, Tehran University of Medical Sci., 2019, 27 (1), pp. 191 - 201.

43. Vidal R.R.L., Desbrières J., Borsali R., Guibal E. Oil removal from crude oil-in-saline water emulsions using chitosan as bio sorbent. Separation Science and Technology, 2020, 55 (5), pp. 835 - 847.

44. Harrington J., Schaefer M. Extrusion-Based Microencapsulation for the Food Industry. In: eds. GAONKAR A.G., Vasisht N., Khare A.R., Sobel R. Microencapsulation in the Food Industry, Academic Press, 2014, pp. 81 - 84.

45. Seth D., Mishra H.N., Deka S.C. Effect of microencapsulation using extrusion technique on viability of bacterial cells during spray drying of sweetened yoghurt. International Journal of Biological Macromolecules, 2017, 103, pp. $802-807$.

46. Bampi G.B., Backes G.T., Cansian R.L., Matos F.E., Araldi-Ansolin I.M., Poleto B.C., Corezzolla L.R., FavaroTrindade C.S. Spray Chilling Microencapsulation of Lactobacillus acidophilus and Bifidobacterium animalis subsp. lactis and its Use in the Preparation of Savory Probiotic Cereal Bars. Food Bioprocess Technology, 2016, 9, 1422 - 1428.

47. Nogueira M., Prestes C.F., Burkert J.F. Microencapsulation by lyophilization of carotenoids produced by Phaffia rhodozyma with soy protein as the encapsulating agent. Food Science and Technology International, 2017, 37, 1 - 4.

48. Piccinino D., Capecchi E., Botta L., Bizzarri B.M., Bollella P., Antiochia R., Saladino R. Layer-by-Layer Preparation of Microcapsules and Nanocapsules of Mixed Polyphenols with High Antioxidant and UVShielding Properties. Biomacromolecules, 2018,19(9), pp. 3883 - 3893.

49. Lu T., Spruijt E. Multiphase Complex Coacervate Droplets. Journal of American Chemical Society, 2020, 142, pp. $2905-2914$.

50.Ang L.F., Darwis Y., Por L.Y., Yam M.F. Microencapsulation Curcuminoids for Effective Delivery in Pharmaceutical Application. Pharmaceutics, 2019, 11 (9), pp. 451.

51.Justi P.N., Sanjinez-Argandoña E.J., Macedo M.L.R. Microencapsulation of Pequi pulp oil by complex coacervation. Revista Brasileira de Fruticultura, 2018, v. 40, n. 2: (e-874).

52. Shu G., He Y., Chen L., Song Y., Meng J., Chen H. Microencapsulation of Lactobacillus Acidophilus by XanthanChitosan and Its Stability in Yoghurt. Polymers, 2017, 9(12), 733.

53. Lombardo S., Villares A. Engineered Multilayer Microcapsules Based on Polysaccharides Nanomaterials. Molecules, 2020, 25, 4420.

54. Gasperini L., Mano J.F., Reis R.L. Natural polymers for the microencapsulation of cells. Journal of the Royal Society Interface, 2014, 11: 20140817.

55. Coghetto C.C., Brinques G.B., Siqueira N.M., Pletsch J., Duarte Soares R.M., Záchia Ayub M.A. Electro-spraying microencapsulation of Lactobacillus plantarum enhances cell viability under refrigeration storage and simulated gastric and intestinal fluids. Journal of Functional Foods, 2016, 24, pp. 316 - 326.

56. Duan Ch., Meng X., Jingru Meng Khan M.I.H., Dai L., Khan A., An X., Zhang J., Huq T., Ni Y. Chitosan as A Preservative for Fruits and Vegetables: A Review on Chemistry and Antimicrobial Properties, Journal of Bioresources and Bioproducts, 2019, 4 (1), pp. 11 - 21.

57. Correa R.F., Colucci G., Halla N., Pinto J.A., Santamaria-Echart A., Blanco S.P., Fernandes I.P., Barreiro M.F. Development of Chitosan Microspheres through a Green Dual Crosslinking Strategy Based on Tripolyphosphate and Vanillin, Molecules, 2021, 26, 2325.

58. Ferreira S., Piovanni G.M., Malacrida C.R.O., Nicoletti V.R. Influence of emulsification methods and spray drying parameters on the microencapsulation of turmeric oleoresin. Emirates Journal of Food and Agriculture, 2019, 31 (7), pp. 491 - 500. 
59. Dewi E.N., Kurniasih R.A., Purnamayanti L. Physical Properties of Spirulina Phycocyanin Microencapsulated with Maltodextrin and Carrageenan. Philippine J. of Science, 2018, 147 (2), pp. 201 - 207.

60. Batista De Oliveira T.T. Microencapsulation of spirulina platensis by spray drying method as a promising alternative for the development of new products. Brazilian Journal of Development, 2020, $6(4)$, p. 2017 - 20186.

61.Prakash A., Soni H., Mishra A., Sarma P. Are your capsules vegetarian or nonvegetarian? - An ethical and scientific justification. Indian Journal of Pharmacology, 2017, 49 (5), pp. 401 - 404.

62. Perinelli D.R., Palmieri G.F., Cespi M., Bonacucina G. Encapsulation of Flavours and Fragrances into Polymeric Capsules and Cyclodextrins Inclusion Complexes: an Update. Molecules, 2020, 25 (24) : 5878.

63. Marfil P.H.M., Paulo B.B., Alvim I.D., Nicoletti V.R. Production and characterization of palm oil microcapsules obtained by complex coacervation in gelatin/gum Arabic. Journal of Food Process Engineering, 2018, 41 (4): e12673.

64. Atgie M. Composition and structure of gum Arabic in solution and at oil-water interfaces. PhD Thesis, 2018, 161p, [accessed 05.08.2021], https://oatao.univ-toulouse.fr/20871/1/ATGIE_Marina.pdf - in French.

65. Hernandez-Nava R., Lopez-Malo A., Palou E., Ramírez-Corona N., Jimenez-Munguía M.T. Encapsulation of Origanum vulgare essential oil by complex coacervation between gelatin and chia mucilage and its properties after spray drying. Food Hydrocolloids, 2020, 109: 106077, 8p.

66. Boudoukhani M., Yahoum M.M., Lefnaoui S., Moulai-Mostefa N., Banhobre M. Synthesis, characterization and evaluation of deacetylated xanthan derivatives as new excipients in the formulation of chitosan-based polyelectrolytes for the sustained release of tramadol. Saudi Pharmaceutical Journal, 2019, 27 (8), pp. 1127 - 1137.

67. Enache I. M., Vasile A. M., Enachi E., Barbu V., Stănciuc N., Vizireanu C. Co-Microencapsulation of Anthocyanins from Black Currant Extract and Lactic Acid Bacteria in Biopolymeric Matrices. Molecules, 2020, 25 (7), 1700.

68. Hernández-Nava R., López-Malo A., Palou E., Ramírez-Corona N. and Jiménez-Munguía M.T. Complex Coacervation Between Gelatin and Chia Mucilage as an Alternative of Encapsulating Agents. Journal of Food Science, 2019, 84 (6), pp. 1281 - 1287.

69. Dimova O., Baerle A. Formation of Microcapsule’s Biopolymeric Shells: Electrochemical Aspects. Journal of Engineering Science, 2018, 2 (1), pp. 90 - 94.

70. Mitchell G.R., Hiremath Ch., Heggannavar G. Biopolymers in Drug Delivery. Applications. In: Green Polymer Composites Technology: Properties \& Applications, Taylor \& Francis, 2015, pp. 551 - 525.

71. Mujica-Álvarez J., Gil-Castell O., Barra P.A., Ribes-Greus A., Bustos R., Faccini M., Matiacevich S. Encapsulation of Vitamins A and E as Spray-Dried Additives for the Feed Industry, Molecules, 2020, 25 (6): 1357.

72. Benetti J.V.M., Nicoletti V.R. Carotenoid stability in spray dried microspheres based on soybean protein isolate microgels. CIPCA 2020. VIII-th International Conference of Food Proteins and Colloids. At: Campinas/SP Brazil. p. 1

73. Malacrida C.A., Ferreira S, Cireli Zuanon L.A., Nicoletti Telis V.R. Freeze-drying for microencapsulation of turmeric oleoresin using modified starch and gelatin. Journal of Food Processing and Preservation, 2014, 39(6), DOI:10.1111/jfpp.12402

74. Li J. The Use of Starch-Based Materials for Microencapsulation. In: eds. Gaonkar A.G., Vasisht N., Khare A.R., Sobel R. Microencapsulation in the Food Industry. Academic Press, 2014, pp. 195 - 210.

75.Gamboa-Carballo J.J., Rana V.K., Levalois-Grützmacher J., Gaspard S., Jáuregui-Haza U. Structures and stabilities of naturally occurring cyclodextrins: a theoretical study of symmetrical conformers, Journal of Molecular Modeling, 2017, 23 (11): 318.

76. De Souza I.A., Orsi D.C., Gomes A.J., Lunardi C.N. Enzymatic hydrolysis of starch into sugars is influenced by microgel assembly. Biotechnology Reports, 2019, 22 : e00342.

77.Jeyakumari A., Zynudheen A.A., Parvathy U. Microencapsulation of bioactive food ingredients and controlled release-a review. MOJ Food Processing \& Technology, 2016, 2 (6), pp. $214-224$.

78.Li Y.O., Dueik González V.P., Diosady L.L. Microencapsulation of Vitamins, Minerals, and Nutraceuticals for Food Applications. In: eds. Gaonkar A.G., Vasisht N., Khare A.R., Sobel R. Microencapsulation in the Food Industry. Academic Press, 2014, pp. 501 - 522.

79. Callegari M.A., Novais A.K., Oliveira E.R., Dias C.P., Schmoller D.L., Pereira J.M., Nagi J.G., Alves J.B., Silva C.A. Microencapsulated acids associated with essential oils and acid salts for piglets in the nursery phase. Semina Ciências Agrárias, 2016, 37 (4), pp. 2193 - 2208. 
80.Zorzenon M., Hodas F., Milani P., Formigoni M., Dacome A., Monteiro A., Costa C., Costa S. Microencapsulation by Spray-drying of Stevia Fraction with Antidiabetics Effects. Chemical Engineering Transactions, 2019, 75, pp. $307-312$.

81. Favaro-Trindade C.S., Rocha-Selmi G.A., Dos Santos M.G. Microencapsulation of Sweeteners. In: ed. Sagis L.M.C. Microencapsulation and Microspheres for Food Applications. Academic Press, 2015, pp. 333 - 349.

82. Sanjay Ch., Jasjeet K., Sandeep K. Liposome Entrapment of Bacteriophages Improves Wound Healing in a Diabetic Mouse MRSA Infection. Frontiers in Microbiology, 2018, 9, p. 561.

83. Pacheco C., González E. Paz R., Parada J. Retention and pre-colon bio accessibility of oleuropein in starchy food matrices, and the effect of microencapsulation by using inulin. Journal of Functional Foods, 2018, 41, pp. 112 - 117.

84. Bortoloti Fernandes T.A., Emerson J.V. Sakanaka L.S., Ueno C.T. Development of immunoglobulin-Y antibody encapsulation process for maintenance viability. In: eds. OLIVEIRA A.F., SHIRAI M.A. Topics in Food Science and Technology: Results of Academic Research. 2020, 5, pp. 115 - 134. - in Portuguese

85. Sturza R., Verejan A., Subotin lu., Haritonov S., Munteanu D., Covaci E. et al. Applied Chemistry for Engineers. Chișinău, Tehnica-UTM, 2021, 356p. - in Romanian

86. Baerle A., Tatarov P., Dimova O., Cojohari C. Process for microencapsulation of food and cosmetic oil compositions. Patent MD-557, BOPI 2012-11-30, p. 32 - 33.

87. Correa R., Colucci G., Noureddine H., Pinto J., Santamaria-Echart A., Monte Blanco S., Fernandes I, Barreiro M. Development of Chitosan Microspheres through a Green Dual Crosslinking Strategy Based on Tripolyphosphate and Vanillin. Molecules, 2021, 26, 2325.

88. Kawazoe Sato A.C., Zagatto Polastro M., De Figueiredo Furtado G., Lopes Cunha R. Gelled Double-Layered Emulsions for Protection of Flaxseed Oil. Food Biophysics, 2018, 13, pp. 316 - 323.

89. Ladha-Sabur A., Bakalis S., Fryer P.J., Lopez-Quiroga E. Mapping energy consumption in food manufacturing. Trends in Food Science \& Technology, 2019, 86, pp. 270 - 280.

90. Monforti-Ferrario F., Dallemand J., Pinedo Pascua I., Motola V., Banja M., Scarlat N. et al. Energy use in the EU food sector: State of play and opportunities for improvement. EUR 27247. Publications Office of the European Union, 2015, JRC96121.

91.Schroen K., Berton-Carabin C., Renard D., Marquis M., Boire A., Cochereau R., Amine C., Marze S. Droplet Microfluidics for Food and Nutrition Applications. Micromachines, 2021, 12 (8), 863.

92. Vallejo R., Gonzales-Valdivieso J., Santos M., Rodriguez-Rojo S., Arias F.J. Production of elastin-like recombinamer-based nanoparticles for docetaxel encapsulation and use as smart drug-delivery systems using a supercritical anti-solvent process. Journal of Industrial and Engineering Chemistry, 2021, 93, pp. 361 - 374.

93. Ghaffarian R., Herrero E.P., OH, H., Raghavan S.R., Muro S. Chitosan-Alginate Microcapsules Provide Gastric Protection and Intestinal Release of ICAM-1-Targeting Nanocarriers, Enabling GI Targeting In Vivo. Advanced Functional Materials, 2016, 26 (20), pp. 3382 - 3393.

94. Dimova O. Behavior of microcapsules containing $\omega 3$ - and $\omega 6$ - polyunsaturated acids from walnut oil in the model of digestive tract environment. Journal of Food and Packaging Science, Technique and Technologies, 2016, 9, pp. 44 - 48.

95. Silva J., Munari Benetti J., Alexandrino T., Assis O., De Ruiter J., Schroën K., Nicoletti V. Whey Protein Isolate Microgel Properties Tuned by Crosslinking with Organic Acids to Achieve Stabilization of Pickering Emulsions. Foods, 2021, 10 (6), 1296.

96. https://www.dpmms.cam.ac.uk/ wtg10/cubic.html - accessed 10.07.2021.

97.Dimova O.V., Baerle A.V., Tatarov P.G., Kiritsa E.N. Fortification of fermented milk products with microencapsulated beta-carotene - Dairy Industry, 2013, 9, pp. 42 - 43. - in Russian.

98. Pateiro M., Gómez B., Munekata P.E.S., Barba F.J., Putnik P., Kovačević D.B., Lorenzo J.M. Nanoencapsulation of Promising Bioactive Compounds to Improve Their Absorption, Stability, Functionality and the Appearance of the Final Food Products. Molecules, 2021, 26, 1547.

99. Trojanowska A., Nogalska A., Valls R.G., Giamberini M., Tylkowski B. Technological solutions for encapsulation. Physical Sciences Reviews, 2017, 2 (9), 20170020.

100. Radu O. Baerle A., Tatarov P., Popescu L. Factors, that determine the shelf life of a butter-like spread, based on walnut oil. Journal of Engineering Science, 2019, XXVI (3), pp. 119 - 124. 